\title{
LA INTRODUCCIÓN DEL LIBERALISMO INGLÉS EN BARCELONA: LO BELLO Y LO SUBLIME DE MANUEL CASAMADA
}

\author{
The Introduction of English Liberalism in Barcelona: \\ Manuel Casamada's The Beautiful and the Sublime
}

\author{
Ignasi ROviRó ALEMANY ${ }^{1}$ \\ Universidad Ramon Llull
}

\section{Resumen}

A principios del siglo XIX los literatos de la capital de España estaban divididos en dos facciones: una progresista y otra conservadora. Estas posiciones ideológicas contaminaron la literatura. Los progresistas utilizaron como bandera un texto retórico del predicador escocés Hugo Blair (1718-1800); los conservadores, un texto del esteta francés Charles Batteux (1713-1780). El uso de Blair representó también una vía más de introducción del pensamiento liberal inglés y la divulgación de Edmund Burke, de especial interés para la oposición entre lo bello y lo sublime. Hasta ese momento, los conceptos de lo bello y lo sublime se entendían como conceptos encadenados. En Barcelona, la influencia de Blair se ve en la obra del fraile liberal Manuel Casamada (1772-1841) y en el discurso, inédito, que pronunció en la Real Academia de Buenas Letras de Barcelona (1837), que ha sido incluido, transcrito y anotado, en este artículo.

Palabras clave: Hugo Blair, Manuel Casamada, bello, sublime, estética

\section{Abstract}

In early nineteenth century, the writers of the capital of Spain were divided into two factions: one conservative and one progressive. These ideological positions were transferred to literature. The progressives used as flag a rhetorical text of the Scottish preacher Hugh Blair (1718-1800), the conservatives, a text of the French

1 Profesor de Estética en la Facultad de Filosofía. Correo electrónico: iroviro@filosofia.url. edu. Este artículo forma parte del proyecto de investigación «La estética española: las ideas y los hombres (1850-1950», FFI2013-42674-P, del Ministerio de Economía y Competitividad. Fecha de recepción del artículo: 22 de julio de 2016. Fecha de aceptación: 1 de septiembre de 2016. 
esthete Charles Batteux (1713-1780). Blair's use represents one route of introduction of liberal English thought and the popularization of Edmund Burke, work of particular interest to the opposition between the beautiful and the sublime. Until then, the concepts of beauty and the sublime understood as linked concepts. In Catalonia, Blair's influence is seen in the work of the Liberal priest Manuel Casamada (1772-1841) and in the speech, unedited, who spoke at the Real Acadèmia de Bones Lletres de Barcelona (1837), which has been included, transcribed and annotated, in this article.

Key words: Hugh Blair, Manuel Casamada, beautiful, sublime, aesthetic

\section{INTRODUCCIÓN ${ }^{2}$}

Las ideas de la Ilustración inglesa se extendieron de forma gradual por toda Europa. En España estas ideas se vieron envueltas por una serie de movimientos políticos e ideológicos de gran alcance, además de una influencia notable de textos franceses. Todo ello formó parte de un movimiento difícil de definir, que a menudo ha llevado a diversos investigadores a afirmar que en España no ha habido una Ilustración, sino más bien unos ilustrados. Sea como fuere, en el terreno de la retórica y de la teoría literaria la influencia británica se reflejó en algunas traducciones de obras inglesas y en dos características propias: un reconocimiento de la tradición y una incomodidad con los planteamientos de la escolástica. Existían, en la España del siglo XVIII, unas tensiones evidentes entre los defensores de la ortodoxia escolástica y los que reclamaban unos cambios de perspectiva que se adaptaran a la nueva efervescencia social. José Rico ha indicado como se llegó a un cierto equilibrio entre estas partes a través de un humanismo cristiano. ${ }^{3}$ Lo cierto es que cuatro grandes figuras marcaron, entre otras y para las humanidades, aquellos tiempos ilustrados: Benito Jerónimo Feijoo, Gregorio Mayans, Gaspar Melchor de Jovellanos y Antonio de Campmany. Todos estos autores buscaron un cierto equilibrio entre la tradición y las nuevas ideas. $\mathrm{Al}$ hacer balance de los resultados en el arraigo y en la divulgación de las ideas ilustradas en el siglo XVIII y primeros años del

2 Un trabajo in extenso sobre esta misma temática vio la luz en 2011 bajo el título «Hug Blair a Catalunya: el discurs sobre El bello i el sublim de Manuel Casamada I Comella». En Ignasi Roviró, ed., Estètica catalana, estètica europea. Estudis d'estètica: entre la tradició i l'actualitat. Barcelona, PPU: 43-80.

3 José Rico Verdú, La retórica española de los siglos XVI y XVII, Madrid, CSIC, 1973, p. 3. 
XIX, podemos dudar de la eficacia de dichos intentos. ${ }^{4}$ El enfrentamiento entre las dos Españas ya había empezado y no sólo era retórico o de teoría literaria, sino que representó, ya a principios del XIX, dos maneras de ver el mundo. ${ }^{5}$

Las investigaciones del grupo liderado por el profesor de la Universidad de Cádiz, el Dr. José Antonio Hernández Guerrero, han puesto de relieve la dificultad de ordenar y clasificar los manuales de retórica y de literatura españoles de principios del siglo XIX ${ }^{6}$ que, de alguna forma, dejaban traslucir aquellas ansias. Por otra parte, lo que no ponen de manifiesto sus investigaciones es el uso ideológico que se hizo de la literatura y de los manuales de retórica en unos momentos tan delicados para la política española; una política donde el papel de los intelectuales fue de suma importancia: la mayoría de los puestos de relevancia política fueron para intelectuales. La literatura era, en los primeros años del siglo XIX, una literatura comprometida. Utilizar uno u otro manual escolar era expresión de profesar un credo ideológico, abanderar unas teorías literarias situaba en un «lugar» ideológico y político.

Don Paul Abbott ${ }^{7}$ ha señalado que es en el Curso de Humanidades castellanas (donde se incluyen las Lecciones de Retórica y Poética) de Jove-

4 Charles Wilbanks, «La retórica cristiano-humanística de Antonio de Capmany», en Helena Beristain y Gerardo Ramírez, comps., Los ejes de la retórica. México, Universidad Nacional Autónoma de México, 2005, p. 279. Wilbanks argumenta que Campmany fue el autor que más éxito tuvo en la expansión de las nuevas ideas literarias y retóricas en España.

5 Es imprescindible la lectura del volumen IV de la Historia crítica del pensamiento español, dedicado al liberalismo y romanticismo (1808-1874), del profesor José Luis Abellán, Espasa-Calpe, Madrid, 1984.

6 José Antonio Hernández Guerrero y M. ${ }^{a}$ Carmen García Tejera, «Propuestas para una nueva lectura de las Retóricas y Poéticas españolas del siglo XIX», en B. Schilicben-Lange y otros, Europäische Sprachwissenschaft um 1800: methodologische und historiographische Beiträge zum Umkreis der «idéologie», 2, Münster, Nodus Publikationen, 1991: 65-83. El grupo de investigación propone una clasificación de los manuales en las siguientes corrientes europeas: sensualismo, sensualismo mitigado o sentimentalismo, espiritualismo, tradicionalismo, neoescolasticismo, krausismo y otras corrientes. El texto de Blair es situado como continuador del clasicismo del siglo XVIII. Se puede ver un resumen de su proyecto en http://www2.uca.es/grup-invest/retorica-actual/proyectos/PROYECTO\% 20RETORICA.htm

7 "The influence of Blair's Lectures in Spain». Rhetorica: A Journal of the History of Rhetoric, 7/3 (Summer 1989), pp. 275-289; y «Blair 'Abroad'. The European Reception of the Lectures on Rhetoric and Belles Lettres», en Lynée Lewis-Gaillet, Scottish Rheoric and its Influences, New Jersey, Hermagoras Press, 1998, pp. 67-78. 
llanos donde se encuentra por vez primera la influencia en España del retórico escocés Hugo Blair. ${ }^{8}$ El libro del predicador escocés, las Lectures on Rhethoric and Belles Lettres, formó a más de una generación en su país, en todo el ámbito anglófono y, a través de la traducción, en otros estados europeos. El texto tuvo más de un centenar de ediciones y de resúmenes. Se tradujo al español, al francés, al alemán, al italiano y al ruso. Según Abbott, fue casi tan influyente en Inglaterra como en España. Encontramos el libro de Blair en la reforma liberal de los planes de estudio de la Universidad de Salamanca que se llevó a cabo en 1807. También se decretó para el estudio de la literatura y la historia en los Reales Estudios de San Isidro del Colegio Imperial de Madrid ${ }^{9} \mathrm{y}$, en 1820, para la retórica en los estudios de humanidades y de teología, según los planes de estudios del gobierno español. ${ }^{10}$

El libro de Blair fue la fuente principal de dos textos más, todos ellos oficiales para los estudios de humanidades: los Principios de retórica y poética de Francisco Sánchez Barbero (1805) ${ }^{11}$ y el Arte de hablar en prosa y verso, de José Gómez Hermosilla. Refiriéndose a Blair, escribe el profesor

8 Hugo Blair (1718-1800) predicador y retórico escocés, considerado como uno de los teóricos más destacados del arte del discurso. De sus principales obras, A Critical Dissertation on the Poems of Ossian, the Son of Fingal (1763), Sermons (5 vols, 1777-1801) y Lectures on Rhetoric and Belles Lettres (1783), ésta última es la que aquí nos interesa. Traducida al castellano y compendiada en varias ocasiones, fue un texto reconocido para la enseñanza oficial hasta 1825 , fecha en que se sustituyó por el texto de José Gómez Hermosilla, Arte de hablar en prosa y verso, Madrid, Imprenta Real, 1826, 2 vol. José Luis Munárriz fue el traductor y adaptador de la obra de Blair al castellano: Lecciones sobre la Retórica y las bellas artes, traducidas y adicionadas a partir del original inglés de Hugo Blair, Madrid, imp. de Antonio Cruzado, 1798-1801, 4 vols.

9 José Simón-Díaz, Historia del Colegio Imperial de Madrid, CSIC, Madrid, 1959, 2, p.148.

10 Así lo determina la Real Orden de 20/09/1820. Abbott (1989: 284) afirma que: «The Arte de hablar [De Gómez Hemosilla] replaced Munarriz' Lecciones de Blair as the humanities textbook officially sanctioned by the Consejo de Castilla» y en nota añade: «At the time of this decision Hermosilla held the position of Secretario de la Inspección General de Instrucción Pública». En el texto de Gómez Hermosilla, de 1826, se indica que por Real Orden de 19/12/1825 la obra se estudie en las clases de humanidades. Pero esto no hizo desaparecer la obra de Blair de las aulas, sino que se mantuvo en la adecuación e integración al Curso elemental de retórica y poética de Alfredo Adolfo Camus (que además del texto de Blair integraba la poética de Sánchez Barbero), texto reconocido por el Consejo de Instrucción Pública y presente en los programas educativos de 1850 (Gaceta de Madrid, 09/28/1850), 1851 (GDM, 05/09/1851), 1852 (GDM, 02/19/1852), 1854 (GDM, 18/10/1854), 1855 (GDM, 14/10/1855), 1856 (GDM, 09/18/1856), 1861 (GDM, 09/27/1861), 1864 (GDM, 09/03/1864) y 1867 (GDM, 09/16/1867).

11 M. José Sánchez de León, «Los principios de Retórica y poética de Francisco Sánchez Barbero en el contexto de la preceptiva de la época» en Actas del X Congreso de la Asociación Internacional de Hispanistas, Barcelona, vol. 2. pp. 1439-1450. 
Soria: «...aparece casi siempre como autoridad rectora de los presupuestos teóricos enseñados en la mayoría de los centros del país y, al mismo tiempo, como impulsor ejemplar de los destinados a dirigir e iniciar la juventud en la teoría y práctica retóricas y críticas». ${ }^{12}$

\section{Blair contra Bateaux}

La traducción española de las Lectures on Rhethoric and belles lettres de Blair (Madrid, 1798-1801) representó un hito para el pensamiento liberal: «This 'liberal document' was especially well suited to late eighteenth and early nineteenth century Spain where eclectic approaches to literary and philosophical issues were quite common».13 El traductor, José Luis Munárriz, no fue fiel al texto, sino que suprimió algunas lecciones (XX-XIV) y en su lugar insertó unos capítulos sobre el examen crítico del estilo de Cervantes y Saavedra; además, añadió un capítulo (XLII) sobre poemas épicos castellanos y algunos apéndices sobre literatura española.

El profesor José Checa ${ }^{14}$ cree que Munárriz tradujo Blair por recomendación de Jovellanos. El hecho al que hemos de atender es que esta traducción fue utilizada como bandera ideológica por parte de un grupo de literatos liberales que se reunían en torno a Manuel José Quintana. Contra este uso ideológico de la literatura se oponía el uso mucho más conservador del grupo capitaneado por Leandro Fernández Moratín. Este grupo utilizaba la traducción española de los Principes de la Littérature de Charles Batteux no sólo para entender el hecho literario sino también como defensa ideológica contra el grupo de Jovellanos. La traducción de los Principes, hecha por García de Arrieta en el 1797, resultaba tan interesada como la de Munárriz. ${ }^{15}$ La polémica entre literatos liberales y conservado-

12 Andrés Soria Ortega, «Notas sobre Hugo Blair y la retórica española en el siglo XIX», en Estudios sobre la literatura y arte: dedicados al profesor Emilio Orozco Diaz, coord. por Nicolás Marín, Andrés Soria y Antonio Gallego Morell, Granada, Universidad, vol. III, p. 363.

13 Don Paul Abbott, «The influence of Blair's Lectures in Spain». Rhetorica: A Journal of the History of Rhetoric, 7/3 (Summer 1989), p. 287.

14 José Checa Beltrán, Razones del buen gusto: poética española del neoclasicismo, CSIC, 1998, p.134. Cf. Andrés Soria Ortega, «Notas sobre Hugo Blair y la retórica española en el siglo XIX». En Nicolás Marín, Andrés Soria y Antonio Gallego Morell, coords., Estudios sobre la literatura y arte: dedicados al profesor Emilio Orozco Díaz. Granada, Universidad de Granada, 1979, vol. 3, pp. 363-368.

15 Para los detalles y el análisis de la traducción, $c f$. Inmaculada Urzainqui, «Batteux español», en Francisco Lafarga (ed.), Imágenes de la Francia en las letras hispánicas, Barcelona, PPU, 1989, pp. 239-260. 
res fue sucia. Una muestra nos la da Juan Tineo Rodríguez, amigo de Moratín, quien, en relación con la traducción de Munárriz escribe, «...obra clásica de la nueva secta, en el nuevo doctrinal poético de los andreses. Tal es la pésima traducción de las Lecciones sobre la Retórica de Blair». ${ }^{16}$

En los Recuerdos de un anciano, Antonio Alcalá Galiano recuerda aquellos tiempos:

La literatura madrileña estaba en 1806 casi dividida en dos bandos [...] La una hueste era patrocinada por el Gobierno, o digamos por el Príncipe de la $\mathrm{Paz},{ }^{17}$ al cual eran los hombres principales o cabos personalmente adictos. Era el principal de estos D. Leandro Fernández Moratín, poeta cómico aventajado, si bien falto de imaginación creadora, y de pasión viva o intensa [...] nada amante de la libertad política, y muy bien avenido con la autoridad, aun la de entonces [...] En el bando opuesto militaban hombres célebres ya entonces [...] Sus ideas eran las de los filósofos franceses del siglo XVIII y las de la revolución del pueblo nuestro vecino [...] En literatura su clasicismo era menos puro que el de sus adversarios, yéndose con los semi-heréticos de los días de Voltaire, cuando los otros se quedaban con los ortodoxos Boileau y Racine. D. Manuel José Quintana [...] era el principal, si no en crédito, en influencia, de los de su parcialidad literaria. [...] Los dos bandos literarios tenían una a manera de catecismo de su fe, o dicho con más propiedad, un libro en que a la par promulgaban sus doctrinas, y en las aplicaciones de éstas daban satisfacción a sus efectos. El libro de los moratinistas eran los principios de literatura de Batteux; el de los quintanistas las lecciones de retórica y poética del escocés Hugo Blair. ${ }^{18}$

Para Marcelino Menéndez y Pelayo este enfrentamiento era mucho más que madrileño, era español:

Así se explica el curioso fenómeno de que todos los espíritus que en España manifestaban alguna propensión a dar mayor ensanche y elevación al pensamiento poético y mayor libertad a las formas líricas, fuesen apasionados partidarios de Blair: así Cienfuegos, Quintana y hasta cierto punto Lista. ${ }^{19}$

16 El editor del Juicio crítico de los principales poetas españoles de la última era. Obra póstuma de Don José Gómez Hermosilla que saca a luz Don Vicente Salvá (Valencia, Librería de Mallén y Sobrinos, 1840, vol. 1) incluye un prólogo de Juan Tineo antes de la selección de las poesías de Juan Meléndez Valdés. La cita se extrae de este prólogo, en la p.184.

17 Nombre con el que se conocía a Manuel Godoy, por haber negociado la paz de Basilea (1795).

18 Antonio Alcalá Galiano, Recuerdos de un anciano, Madrid, Imprenta Central, 1878, pp. 63-67. Alcalá retoma la cuestión en Historia de la literatura española, francesa, inglesa e italiana en el siglo XVIII. Lecciones pronunciadas en el Ateneo de Madrid, Imprenta de la sociedad literaria y tipográfica, Madrid, 1845, pp. 436 a 465.

19 Marcelino Menéndez y Pelayo, Historia de las ideas estéticas en España, CSIC, Madrid, 1994, vol. 1, p. 1160. Poco antes había escrito: «El grupo que acaudillaban Quintana y Cienfuegos, y que venía a ser la última evolución de la escuela salmantina informada ya 
No tenemos conocimiento de este enfrentamiento literario-ideológico ni en Barcelona ni en el resto de Cataluña. No hay estudios sobre la influencia sobre la literatura y la utilización ideológica de Blair. Manuel Casamada representa la recepción del escocés en Barcelona. ${ }^{20}$ Por ser un autor hoy muy desconocido dedicamos unas notas bio-bliográficas sobre el autor del Discurso sobre lo bello y lo sublime.

\section{Manuel Casamada y su obra}

Manuel Casamada nació en Barcelona el 9 de septiembre de 1772 en el seno de una familia acomodada. ${ }^{21} \mathrm{~A}$ los 15 años entró en el colegio y con-

de un poderoso espíritu enciclopedista y revolucionario, tomó por bandera las Lecciones de Blair, en cuyos suplementos el mismo Quintana y el mismo Cienfuegos, y además Sánchez Barbero y otros, habían puesto la mano. Los adversarios de Quintana, es decir, el grupo acaudillado por Moratín el hijo, se dieron, por espíritu de contradicción, a patrocinar al infeliz traductor del Batteux, pero sin ayudarle con otro más positivo servicio que con decir pestes de la traducción de Blair, que ciertamente las merecía todas, ni más ni menos que la de su rival, pudiendo tenerse una y otra por pésimas entre las malas de aquel siglo». (ibid, p. 1159). Muy posteriormente ha seguido señalando el enfrentamiento M. José Rodríguez Sánchez de León, en «Batteux y Blair en la vida literaria española a comienzos del siglo XIX» (1993, p. 234): «Las disputas de Arrieta y Munárriz evidencian de qué manera a comienzos del siglo XIX los preceptistas, los escritores y periodistas y, en general, los hombres de letras colocan la literatura y las disciplinas encargadas de su estudio a disposición de intereses sociales y políticos».

20 James Mandrell en «Lo sublime literario en la poesía española de los siglos XVIII y XIX: Meléndez Valdés y Espronceda» dice encontrar influencias del pensamiento Burke en $E l$ estudiante de Salamanca de Espronceda. Esta interesante posibilidad habría que mostrarse con más rotundidad. (Mandrell, 1993, pp. 207-216).

21 Sobre la biografía de Casamada, pueden consultarse las siguientes obras: Enciclopedia Universal Ilustrada Europeo-Americana, vol. XII, Madrid, Espasa-Calpe; Josep Rafael Carreras «Estudis biogràfics d'alguns benemèrits patricis qui ilustren aquesta Acadèmia». Boletín de la Real Academia de Buenas Letras de Barcelona, 13/100-101 (1928) pp. 377-379. Juan Corominas, Suplemento a las Memorias para ayudar a formar un diccionario crítico de los escritores catalanes... Burgos, Imprenta de Araniz, 1849, p. 73; Guillem Díaz-Plaja, «Una càtedra de retòrica, 1822-1835», Boletín de la Real Academia de Buenas Letras de Barcelona, 29 (1961-1962), pp. 47-79; Faustino D. Gazulla, «Los mercedarios en la Real Academia de Buenas Letras de Barcelona». Boletín de la Real Academia de Buenas Letras de Barcelona, vol. 14, núm. 103 (1930), p. 125; José Antonio Garí y Siumell, Biblioteca mercedaria, ó sea escritores de la Celeste, Real y Militar Orden de la Merced, redención de cantivos..., Barcelona, Imprenta de Herederos de la viuda Pla, 1875, pp. 59-60; Antonio Elías de Molins, Diccionario biográfico y bibliográfico de escritores y artistas catalanes del siglo XIX, Barcelona, 1889; Alfredo Sáez-Rico, La educación generalen Cataluña durante el Trienio Constitucional, Barcelona, Facultad de Filosofía y Letras, UB, 1973, p. 131-136; y Félix Torres Amat, Memorias para ayudar a formar un diccionario crítico de los escritores catalanes, y dar alguna idea de la literatura de Cataluña, Barcelona, Impr. J. Verdaguer, 1836, p. 166. 
vento de San Pedro Nolasco de la orden de la Merced, en Barcelona, donde se formó y se ordenó sacerdote. Durante los años 1792-1795, cursó en su convento Fundamentos de religión, Instituciones teológicas, Escritura, Moral y Cánones. En 1798 obtuvo el doctorado en teología. Después de casi diez años en el convento de $\mathrm{Vic}^{22}$ se desempeñó como regente de estudios del colegio de San Pedro Nolasco de Barcelona y ya en el 1815 era el máximo responsable de dicho convento. Ejerció como examinador sinodal de Girona y director general de estudios de la orden de la Merced en Cataluña. El 30 de marzo de 1815 fue elegido miembro de la Real Academia de Buenas Letras de Barcelona.

El 25 de octubre de 1820 el rey Fernando VII sancionó la ley de reforma eclesiástica, por la que se suprimían monasterios, se reducían conventos y se prohibía admitir novicios y profesiones religiosas. Los artículos 13-15 promovían y facilitaban la secularización de los frailes regulares. Cuatro meses después de entrar en vigor esta ley, concretamente el 16 de febrero de 1821, Manuel Casamada presentó al obispo de Barcelona Pablo Sichar, la petición de secularización. ${ }^{23}$ El obispo firmó la aceptación cinco días después, haciéndose efectiva el 16 de abril de 1821. Casamada dejaba la orden de la Merced y, como sacerdote, pasaba a disposición del obispo.

Formó parte del claustro de profesores del primer intento de restauración de la Universidad de Barcelona, durante el Trienio Liberal. Impartió la asignatura de literatura e historia, que era sufragada por el Ayuntamiento de Barcelona. Poco más tarde, fue catedrático de Teología (impartida en el Seminario de Barcelona, con el reconocimiento de la titulación por parte de la Universidad). De esta misma institución, y después de los exámenes prescriptivos y del reconocimiento de los cursos

22 En el 1799 dirigió en aquel convento unas disputadas cuestiones de teología: Sacrae religionis dogmata questionibus scolasticis ac historicis adornata quae publicae exponunt arenae Fr. Cosmas Lupresti et Bruguera et Fr. Petrus Nolasco Jaques et Artigas reg. Ac milit. Ord. B. M. de Mercede redeptionis captivorum, medius inter ipsos erit P. Fr. Emmanuel Casamada et Comellas in praedicto Ordine Sacrae Theologiae Lector... die II Junii anni a nat. Domini MDCCXCIX... Vici in offic. Mariae Dorca Viudae, eam regente Joanne Dorca. Permaneció en Vic como comendador del convento de la Merced hasta la invasión napoleónica de 1808 y combatió a los franceses como miembro de la Junta del corregimiento de Vic, organizando la defensa de la ciudad, según apuntan Miquel Furriols, «La junta corregimental de Vich en la Guerra de la Independencia». Ausa, 2/12 (1955), pp. 67-79; y Maties Ramisa Verdaguer, "Aspectes de la Guerra del Francès a Vic (18081814)». Ausa, 11/110-111 (1984), pp. 239-249.

23 Archivo Episcopal de Barcelona, Secularizaciones, caja 6. Expediente de Manuel Casamada. 
estudiados en su convento, el 3 de mayo de 1823 recibió el bachillerato en Teología y el 19 de junio del mismo año, el doctorado en la misma disciplina. ${ }^{24}$ Con el regreso del absolutismo Casamada fue profesor sustituto de la cátedra de teología de la Universidad de Barcelona, pero en condiciones precarias: sólo impartía cuando había un número suficiente de alumnos matriculados. ${ }^{25}$ Un cierto aire de incomodidad y de «revanchismo ideológico» se percibe en la documentación: al inicio de 1839 Casamada pidió a la universidad el trato de profesor titular, con voto. Poco antes de terminar el enero de 1839 la Universidad le denegó este reconocimiento aduciendo que tenían preferencia los profesores que se incorporaban de la extinta Universidad de Cervera y los propios de los Estudios Generales de Barcelona (antecedente de la restaurada Universidad). ${ }^{26}$ Casamada buscó sustento en la enseñanza de la latinidad en el colegio de Josep Carreras de Barcelona. ${ }^{27}$

24 Antonio Palomeque, El Trienio Constitucional en Barcelona y la instauración de la Universidad de segunda y Tercera Enseñanza, Barcelona, Facultad de Filosofía, 1970, pp. 199 y 202. Cabe destacar también la labor pedagógica de Casamada: el 21 de agosto 1821, pocos meses después de su secularización y buscando sostenimiento, el Diario Constitucional, político y mercantil de Barcelona anunciaba la apertura de un colegio privado de humanidades bajo su dirección (pp, 3-4). El diario El Universal de Madrid reproducía el anuncio y añadía: «Multiplíquense entre nosotros los medios de instrucción y entonces serán las ideas liberales una necesidad para cuantos tienen la fortuna de pertenecer a esta nación magnánima». 30/08/1821, p. 931), pero la epidemia de fiebre amarilla que asolaba la ciudad impidió que la iniciativa prosperase. A consecuencia de aquella peste murió el padre Joaquín Catalá (1822), fundador de la Academia Cívica y Gratuita de Barcelona, dedicada a la formación de ciudadanos de extracción humilde y la educación de ciegos y sordomudos. En marzo de 1822, el ayuntamiento designó como sustituto a Manuel Casamada quien regentó esta institución hasta la desaparición de la Academia, en 1823.

25 En un informe interno de la Universidad de noviembre de 1837 se lee: «Los matriculados en Teología sólo ascienden a cinco y, por ahora, es suficiente un solo catedrático, pero siempre que convenga darán las lecciones interinamente don Manuel Casamada...»Cf. Antonio Palomeque, Los estudios universitarios en Cataluña bajo la reacción absoltista y el triunfo liberal hasta la reforma de Pidal (1824-1845), Barcelona, Facultad de Filosofía-UB, 1974, p. 261.

26 Antonio Palomeque Torres, Los estudios Universitarios en Cataluña..., 1974, pp. 393-399.

27 «[Manuel] Milá [i Fontanals] fué llevado por su padre a la escuela, que lo era a la sazón de primeras letras, de D. José Carreras [...] recientemente abierto en esta ciudad [...] Juntos estudiamos en dicha escuela dos años de latín bajo la dirección de D. Manuel Casamada, religioso exclaustrado, que con tratarnos á todos sus discipulos con afecto y familiaridad como de padre, distinguió siempre á Milá con especial cariño». Joaquim Rubió i Ors, Noticia de la vida y escritos de D. Manuel Milá y Fontanals, Barcelona, Jaime Jepús Roviralta, 1887, pp. 10-11. 
Casamada fue un liberal que predicaba a favor de causas ideológicas. Tuvo un papel relevante en la proclamación de la libertad, en el apoyo a la reina, en la oposición a hechos de armas absolutistas o la invasión francesa y en la defensa de la Constitución; ${ }^{28}$ participó en actos públicos en apoyo de la restauración de la Constitución de 1812, tuvo intervenciones de comisario político... Fue defensor del moderantismo liberal, de suficiente arraigo en la Barcelona entre 1820-1823, siendo socio del Gabinete de Lectura, el centro neurálgico del moderantismo. Expresando las opiniones políticas de este círculo, y junto con Buenaventura C. Aribau, fue redactor del Diario de la cindad de Barcelona o sea El Eco de la ley. El profesor Jordi Roca Vernet señala dos aspectos interesantes de Casamada como militante de dos sociedades secretas muy destacadas durante el Trienio - la Sociedad del Anillo y la de los Comuneros- y como miembro activo de la Tertulia Patriótica de Lacy, un núcleo muy influyente en la política radical barcelonesa de aquellos años. ${ }^{29}$

Casamada fue, además, el predicador más solicitado para impartir los sermones de efemérides ideológicas y políticas. ${ }^{30} \mathrm{Su}$ militancia le acarreó enfrentamientos ideológicos con otros oradores en un período en que los verdaderos campos de batalla (antes de acudir a las armas) fueron los púlpitos y las imprentas. ${ }^{31}$

Pasado el Trienio Liberal y ya iniciada la Década Ominosa se procedió contra Casamada. El obispo de Barcelona determinó su confinamiento en el convento mercedario de San Ramón de Portell, en la comarca catalana de la Segarra. ${ }^{32}$ Hasta su muerte Casamada malvivió de las pocas clases en la universidad y de la docencia privada en el colegio Carreras.

28 Impartió el sermón oficial del Ayuntamiento constitucional de Barcelona (9 de septiembre de 1822) en la celebración del fracaso de la sublevación de la Guardia Real en Madrid contra la constitución.

29 La tesis del dr. Roca Vernet, Política, liberalisme i revolució. Barcelona, 1820-1823, presentada en la Universidad Autónoma de Barcelona en 2007, es una investigación muy valiosa sobre las vicisitudes barcelonesas durante el Trienio Liberal, siendo de una importancia especial para conocer las sociedades secretas y los movimientos cívicos.

30 Gaspar Feliu, La clerecia catalana durant el Trienni Liberal, Barcelona, Institut d'Estudis Catalans, 1972, p. 126.

31 La primera discusión abierta fue provocada por el padre Aragonés al criticar, desde las páginas del Diario de Barcelona, dos sermones predicados días antes, uno de ellos seguramente de Casamada (Feliu, 1972, p.153). Feliu nos informa también que en la reorganización parroquial de Barcelona en 1822 se favoreció a los secularizados defensores de la causa liberal. A Casamada se le asignó la regencia de la nueva parroquia de la Virgen de la Merced (Feliu, 1972, pp. 99-100).

32 La reclusión no debió durar demasiado tiempo puesto que se lo detecta ya predicando en Barcelona en 1827. Cf. Cayetano Barraquer, La casa de religiosos de Cataluña durante el primer tercio del siglo XIX. Barcelona, Altés y Alabart, 1906, vol 1, p. 1033. 
Este «distingido retórico, profundo filósofo y elocuente orador» ${ }^{33} \mathrm{mu}-$ rió en Barcelona el 7 de noviembre de 1841. Su obra comprende 3 libros, ${ }^{34}$ 12 sermones $^{35}$ y un discurso ${ }^{36}$ inédito, hasta ahora no publicado: es la «di-

33 Cf. Josep Rafael Carreras Bulbena, Estudis biogràfics..., 1928, v. 2, p. 379.

34 Curso elementar [sic] de elocuencia por D[on] M[anuel] C[asamada] y C[omella] $P$ [rebero]. Barcelona, imprenta de José Torner, 1827. 248 p.; Curso elementar [sic] de poesía por D[on] M[anuel] C[asamada] y C[omella] P[rebero]. Barcelona, Imprenta de José Torner, 1828. 386 p.; y Curso de gramática latina: según el método de las gramáticas de las lenguas vivas. Barcelona, Imprenta de Manuel Saurí, 1829, vol. I, 323 p.; vol. II, $225 \mathrm{p}$.

35 Son la parte más visible de la ideología y del combate liberal de Manuel Casamada. Estos son los títulos abreviados. 1814: La Confianza en Barcelona en María de las Mercedes. 1815: Barcelona victoriosa por su fidelidad contra los enemigos extrangeros y por su lealtad contra los traidores domésticos. 1815: Un Heroísmo singular modelo de si mismo: discurso que en el día 27 de junio del año 1815, aniversario de la gloriosa muerte de Ramón Mas, Julián Portet y Pedro Lastortras, sacrificados por el gobierno intruso en igual dia del año 1809. 1815: Las víctimas sacrificadas a los amaños de la más negra porfidia. 1816: Deberes de la piedad y de la gratitud para con unos hermanos difuntos que perecieron por no poder sufrir los desprecios de la religión santa y las desgracias de la patria. 1818: Un sabio sin igual, que con una ciencia bumilde y amante confesó en sus escritos de un modo original los extravíos de su corazón. 1819: La Muger sabia y prudente que á un tiempo poseyó en el trono las virtudes domésticas y sociales: elogio fúnebre que en las solemnes exequias tributadas por su S.E. la Real Audiencia del principado de Cataluña a la gloriosa memoria de S.M. la reyna católica de las Españas doña María Isabel Francisca de Braganza. 1820: Tributo de gratitud a las víctimas del Dos de Mayo de 1808. 1820: La constitución politica de la Monarquía española base de nuestra felicidad, cuando está apoyada y sostenida por las virtudes sociales. 1822: El imperio de las leyes sostenido y afianzado por las víctimas del 7 de julio de 1822 en Madrid. 1837: La Religión cristiana obra de la sabiduría de Dios en su establecimiento y del poder de Dios en su propagación. 1837: Corrupción del corazón y orgullo del entendimiento: dos fuentes de la impiedad.

36 Pronunció algunos discursos ideológicos en la Tertulia de Lacy. Tenemos constancia de ello por la crónica que publicó Joaquín de Alcántara en el Diario Constitucional, político y mercantil de Barcelona, resumiendo la sesión del día 22 de noviembre de 1822: «El secularizado Casamada ocupó la tribuna y en su elocuente discurso manifestó de un modo no fácil de resumir el origen del despotismo, empezando por el poder primario del pueblo, que poco a poco perdió su soberanía. Se remontó a la guerra de la independencia por los mejores ejemplos históricos e hizo ver que en ella el pueblo español recobro la suya y su dignidad formando una constitución, modelo de constituciones, arreglada en parte a las antiguas leyes de Aragón en que se establecía el rico axioma de: no los reyes forman los pueblos, y si los pueblos a los reyes. «Esta nación (dijo) perdió en 1814 los derechos adquiridos con su sangre, pero vueltos a adquirir por la invencible espada de Riego, no los volverá a perder jamás: ante sí, dará la libertad a la Europa y algo más, pues importa poco que todos los tiranos del mundo, cuando menos un Baron de Eroles tan atravesado de corazón como de ojos, seguido por los que ha seducido, atente contra ellos, si nosotros resueltos les oponemos una decisión verdaderamente española y el grito aterrador de los déspotas: Constitución o muerte». Concluyó con 
ferencia entre lo bello y lo sublime». Como ya hemos indicado, este discurso de Manuel Casamada representa el impacto del liberalismo inglés en Cataluña, especialmente a través de Hugo Blair y Burke.

La recepción del liberalismo inglés se hace a través de la preceptiva: es por ello que en el discurso se establece la separación entre lo sublime en los escritos y lo sublime en la experiencia. Pero lo sublime en la preceptiva no era una exclusividad de esa corriente filosófica sino que contaba con una larga tradición escolar y un texto fundador: Sobre lo sublime, de Longino. ¿Qué es pues lo que hace del discurso de Casamada una recepción del modelo estético británico? Esencialmente que plantea lo sublime absolutamente alejado de lo bello. En los modelos estéticos anteriores - especialmente los neoclásicos imperantes entonces en las poéticas y preceptivas españolas y francesas-, entre lo sublime y lo bello existía una continuidad evidente y acababa plasmándose, siempre, en el estilo. El primer texto útil para los universitarios españoles sobre estética, que se publicará nueve años después del discurso de Casamada, mostrará aún esta línea continua entre los dos conceptos. Su autor, Manuel Milà y Fontanals, escribe: «Sin embargo de las diferencias establecidas entre lo propiamente bello y lo sublime, no por esto deben dejarse de considerar como dos grados de belleza». ${ }^{37}$ Si Milá en el 1848 estaba defendiendo la continuidad entre los dos conceptos, Casamada en el 1837 ya había roto la transición entre lo bello y lo sublime, y lo había hecho a través de la obra de Blair y de Burke. ${ }^{38}$

los vivas a la Constitución, a las Cortes, al Rey por la Constitución etc., y después el ciudadano jefe político abrazándole, añadió «Vivan los buenos ministros del culto.» (edición del 25/11/1822, p. 3-4).

Encontramos una nota intrigante en el libro $2^{\circ}$ de las «Actas de las sesiones de la Academia de Buenas Letras de Barcelona». Se consigna que un año después del discurso sobre la diferencia entre lo bello y lo sublime (que transcribimos y anotamos a continuación), concretamente el 18 de noviembre de 1838, Casamada expuso en la Real Academia un «examen crítico de las dos gramáticas castellanas publicadas por Don Vicente Salvá y Don José María Moralejo». Conocer este segundo discurso, hoy perdido, hubiera sido importante para contrastar o confirmar las posiciones ideológicas de Casamada.

37 M[anuel] M[ila y Fontanals], Manual de Estética, Barcelona, Imp. Pons, 1848, p. 18

38 Para la ampliación de este tema, véase el libro de Baldine Saint Girons, Le sublime, Desjonqueres, 2005. La autora afirma que en la historia del concepto ha habido cuatro grandes paradigmas: el de Longino, el de Vico, el de Burke y el de Kant. En el contexto de nuestro estudio, el libro de la profesora Saint Girons pone de manifiesto la importancia de que Casamada adopte un modelo de lo sublime que rompe el paradigma establecido hasta entonces. 
Cuando Casamada escribió el discurso, tenía las obras de estos pensadores enfrente y las seguía hasta tal punto que a veces copia literalmente los ejemplos, la letra y los conceptos. Y cuando entre los textos consultados hay oposición o contradicción, Casamada suele adoptar el criterio de Blair: así lo hace en un tema que es crucial para romper la continuidad entre lo bello y lo sublime: el terror. Burke revoluciona la estética europea emparejando lo sublime - gran tema de debate entre los autores del siglo XVIII-, con el terror.

Blair, adoptando esta misma posición de Burke, la matiza afirmado que es uno de tantos otros medios para llegar a lo sublime, como por ejemplo la fuerza y el poder. Estos dos elementos se encuentran en toda experiencia de lo sublime, mientras que, siguiendo el pensamiento de Blair, el terror no cubre toda la gama de lo sublime. Casamada, sintiéndose en el círculo de ideas de Burke, acepta la corrección de Blair y hace una cierta combinación, dentro de lo posible, entre ambos. Terror y esfuerzo son para Casamada dos elementos esenciales para acceder a lo sublime. También es de Blair la división que hace Casamada de lo sublime, el recurso a los paisajes (como lo es también de tantos otros), la violencia de los elementos naturales, la fuerza y el poder de la naturaleza, el sonido terrible, la luz que hiere a la vista, la oscuridad, la soledad, el silencio, el desorden, la magnanimidad, lo sublime moral en el heroísmo y el recurso al libro de Habacuc. Todos estos elementos los retiene del pensador escocés. Por el contrario, el recurso a la infinitud, la citación de Virgilio, el ejemplo del Leviatán y el del Satanás de Milton los copia de Burke.

Manuel Casamada comprendió que seguir afirmando el nexo de continuidad entre lo bello y lo sublime le llevaba al conservadurismo del pensamiento neoclásico, muy presente aún en las poéticas de su tiempo. Un conservadurismo que tendría una expresión política en las posiciones del pensamiento absolutista y reaccionario que se plasmaba también en los textos escolares y las preceptivas literarias que iban buscando la manera de pervivir en el tiempo. El discurso de Casamada es un paso importante para situar la estética que se hacía en Barcelona en el corazón de la discusión europea más destacada.

Entramos ya a presentar, como punto final de este artículo, la edición anotada de su discurso sobre las diferencias entre lo bello y lo sublime. Para su transcripción, hemos mantenido del texto todas las características del original, adecuando sólo la ortografía a las normas actuales. 


\section{Diferencia ENTRE LO BELLO Y LO SUBLIME: el discurso de Manuel Casamada en la Real ACADEmia de Buenas Letras ${ }^{39}$}

«Disertación leída en la Academia de Buenas Letras por el socio Manuel Casamada en la sesión del día 31 de Marzo de 1837».

«Discurso pronunciado en la Academia de Buenas Letras el día 31 de Marzo de 1837».

«Fue adagio común entre los antiguos griegos que la Poesía era obra de la naturaleza y la elocuencia obra del arte; pero faltos de crítica se equivocaron torpemente. La naturaleza sola, que forma los poetas, es la que enseña a los hombres el ser elocuentes en los grandes intereses y en las pasiones fuertes, que son los dos manantiales de los discursos sublimes y grandiosos..$^{40} \mathrm{El}$ que se halla agitado del interés y de la pasión ve las cosas en otro aspecto, que los demás hombres. Se agolpan en su fantasía las ideas sublimes; y casi sin advertirlo transmite a cuantos le oyen una parte del fuego que lo abrasa.

Dijo bien Addison ${ }^{41}$ que la elocuencia tiene su origen en el corazón ${ }^{42}$ y que los preceptos solo sirven para dirigir el rumbo de las pasiones sin amortiguar su vuelo; ${ }^{43}$ y para evitar los derrumbaderos en que no pocos se precipitaron por falta de gusto y de crítica. ${ }^{44} \mathrm{He}$ aquí la diferencia en-

39 Real Academia de Buenas Letras de Barcelona, UI 39, Legajo 18, número 5.

40 En el Curso elementar de elocuencia, Casamada hace preguntar al discípulo porque la definición clásica de elocuencia es falsa. El maestro responde: «...Porque supone que la elocuencia es obra del arte, cuando lo es de la naturaleza; pues ella sola enseña a los hombres a ser elocuentes en los grandes intereses y en las pasiones fuertes, que son las dos fuentes de los discursos sublimes y verdaderos», p. 6.

41 Joseph Addison (1672-1719). Escritor y político inglés, autor de varias piezas literarias. Traductor de las Geórgicas de Virgilio. Redactor de The Spectator, The Tatler y The Guardian.

42 Cf. la recopilación de sus contribuciones en The Tatler, The Spectator, The Guardian y The Freehold en: Joseph Addison, Moral and Humorous also Essays on Imagination and Taste, Edinburgh, W.\& R Chambers, 1839, en especial el cap. «Eloquence in Affliction», pp. 107-108. Cf. también The Spectator, 633, (Wednesday, December 15). London, Tonson, 1729, The Tenth Ed., vol VIII, (cf. p. 287-291); y The Guardian, London, Tonson, 1714. vol. I. (Tuesday, june 9, 1713): «Those parts of learning which relate to the Imagination, as Eloquence and Poetry, produce an immediate Pleasure in the Mind». (p. 326)

43 The Guardian, volume the first. London, Tonson, 1767, núm. 37, Thursday, april 23, 1713: «Learn, mortals, from my precepts to control the furious passions, the disturb the soul». (p. 148)

44 Cf. Joseph Addison, Moral and Humorous also Essays on Imagination and Taste, 1839, en especial los capítulos «On Taste» (pp.111-112) y «On the Imagination» (p. 112-122). Los preceptos, escribe Casamada en el Curso elementar de elocuencia, «sirven para 
tre lo bello y lo sublime, pues si en lo primero tiene el arte su principal influjo, en lo segundo es la sola naturaleza la que lo puede producirlo, no solo en los objetos, sino también en su descripción por medio del lenguaje y del estilo. Probar estos dos extremos es el asunto que me he propuesto; asunto propio de nuestro instituto ${ }^{45} \mathrm{y}$ conforme a los rápidos progresos que va a obtener la literatura española en la feliz época de nuestra libertad.

Es de admirar por cierto el prolongado silencio que observaron sobre lo sublime los grandes ingenios de la Grecia y de Roma. Homero y Virgilio, Demóstenes y Cicerón, valiéndose de objetos grandiosos y elevados nos presentan en sus escritos las ideas más sublimes y nerviosas; pero ninguno de ellos se ocupó de indagar el origen de esta sublimidad que eleva los ánimos sobre su estado ordinario y que los llena de pasmo y asombro. Longino fue el primero que señaló con poca exactitud y crítica cinco fuentes del sublime. Parece que la indagación filosófica sobre esta materia estaba reservada a los modernos. Hugo Blair, Edmundo Burke, ${ }^{46}$ Rollin, ${ }^{47}$ Arnaud, ${ }^{48}$

señalar las huellas de los primeros maestros y oradores, según en ellos las trazó la naturaleza; sirven para dirigir el rumbo de las pasiones y de la fantasía, sin amortiguar su vuelo; sirven para evitar los derrumbaderos en que otros se despeñaron por falta de gusto y crítica; sirven últimamente para no dejarnos deslumbrar con una elocuencia falsa y pomposa, y aprender a discernir las bellezas genuinas de las espurreas». (p. 7).

45 Se refiere a la Real Academia de las Buenas Letras de Barcelona.

46 Edmund Burke (1729-1797). Filósofo, escritor y político inglés, llamado el Cicerón británico, considerado el padre del liberal-conservadurismo. Sus escritos se encuentran en The Writing and speeches of Edmund Burke (Oxford University Press, 9 vols. 1981- ), entre ellos, destacamos A Philosophical Enquiry into the Origin of Our Ideas of the Sublime and Beautiful, compuesto en 1757 (Traducido al castellano)

47 Charles Rollin (1661-1741). Humanista e historiador francés. Si bien sus obras de historia tuvieron una alta divulgación, su influencia más destacada se produjo en el terreno de la educación de las humanidades. Casamada se refiere a una obra muy conocida y traducida a varias lenguas, De la manière de enseigner et d'estudier les belles lettres par rapport à l'esperit et au coeur, en cuatro volúmenes (París, 1726-1728). El segundo, trata de la retórica y prácticamente está dedicado por completo a la elocuencia. En un capítulo estudia el concepto de lo sublime «Le vrai sublime consiste dans une manière de penser noble, grande, magnifique; et il suppose par conséquent dans celui qui écrit ou qui parle un esprit qui n'ait rien de bas ni de rampant, mais qui soit au contraire rempli de hautes idées, de sentiments généraux, et de je ne sait quelle noble fierté qui se fasse sentir en tout. Cette élévation d'esprit et de style doit être l'image et l'effet de la grandeur d'âme». (pp. 85-86, en la edición de 1736).

48 François Arnaud (1721-1784). Bibliotecario, periodista, miembro de la Academia Francesa y hombre de iglesia. Sus obras completas, en 3 vols. están editadas en París por Léopold Collin. Destacamos el Discours sur l'elocuence romaine (vol. 2, pp. 115-123) y Sur le Style de Platon (vol. 2, pp.157-194) 
Burga y Martínez de la Rosa ${ }^{49}$ son los que han escrito en esta parte con más finura y crítica; y si bien no son conformes en todo sus opiniones, lo son a lo menos en cuanto a distinguir lo sublime de lo bello y a marcar la diferencia de sublimidad entre los objetos y los escritos.

Todos en efecto convienen en que son objetos sublimes las vastas e ilimitadas perspectivas que nos presenta la naturaleza, como las llanuras inmensas cuyo término no alcanza la vista, el firmamento del cielo y la interminable expansión del océano. Tales objetos, dice Burke, causan asombro y suspenden en el ánimo todos sus movimientos con cierto grado de horror. En este caso está el ánimo tan lleno de su objeto que no puede dar entrada a otro alguno no de consiguiente raciocinar sobre el que le ocupa. De aquí nace el grande poder de lo sublime, que lejos de ser parto de nuestros discursos los anticipa y los precede. Es en segundo lugar objeto sublime un sonido muy vehemente, por ejemplo el estallido de un trueno o de un cañón, el bramido de de los vientos y el ruido de las aguas que se desprenden de los peñascos. Todo lo que es terrible con respeto a la vista o al oído, es a la par sublime: no es posible mirar como frívola y despreciable una cosa que puede ser peligrosa. Los terremotos, los volcanes, los grandes incendios, los huracanes y toda violencia de los elementos estremecen el corazón humano y excitan siempre ideas sublimes.

El gran poder y la fuerza puestos en ejercicio son otra fuente de sublimidad..$^{50}$ Un arroyo que corre plácidamente en su cauce es un objeto bello; pero cuando sale de madre con la impetuosidad y estrepito de un torrente, es ya un objeto sublime. Se ve con placer un caballo hermoso que da brincos en un paseo y juguetea con manos y pies; pero aturde y espanta un caballo que en el combate se arroja sobre el enemigo y manifiesta su furor con su crin encrespada. De estos objetos se valen los Poetas para formar sus descripciones y presentar con viveza a la imaginación los espectáculos más fuertes y magníficos. El terror es sin duda una causa principal de la

49 Francisco Martínez de la Rosa (1787-1862). Político y literato español. De sus obras propedéuticas se destaca una poética, donde se lee: «...cualidades esenciales de lo sublime, la grandeza y elevación en el sentimiento, en la imágen o en la idea, y la mayor sencillez en la expresión». (Obras literarias de D. Francisco Martínez de la Rosa. Tomo primero, París, Julio Didot, 1827). En Poética, p. 100.

50 Contra Burke, Blair escribe: «Yo creo, que el mucho poder, esté o no acompañado de terror, ya empleado en protegernos, ya en amedrentarnos, se puede tener con mas razón por calidad fundamental del sublime: pues bien examinado todo, no veo objeto alguno sublime, en cuya idea no entren directamente el poder y la fuerza». (Lecciones..., I, 72.) 
sublimidad: $:{ }^{51}$ y de ahí es que muchos animales, no obstante su pequeñez, son capaces de excitar ideas sublimes, porqué se consideran como objetos de terror: tenemos una prueba de esta verdad en los animales venenosos. Contribuyen en cuarto lugar a lo sublime cuantos objetos se acercan a lo terrible; tales son la obscuridad, la soledad y el silencio. ${ }^{52}$ Los países alegres, los campos esmaltados de flores, las ciudades florecientes no elevan por cierto nuestros ánimos: causan sí en ellos una sensación sublime las montañas mohosas, los lagos solitarios, las florestas y selvas intransitables. El firmamento tachonado de estrellas, esparcidas en tanto número y con tan magnífica profusión hiere la fantasía con una grandeza más respetuosa que cuando está iluminado con todo el resplandor del sol. El sonido profundo de una campana es grande en cualquier tiempo, pero lo es máximamente cuando se percibe en medio del silencio y de la calma de la noche. ${ }^{53}$

Cualquiera se hará cargo de esta verdad, si considera cuanto aumenta la noche nuestro temor en todos los casos de peligro y cuanta impresión hace la obscuridad en nuestros ánimos. Los gobiernos despóticos que tienden siempre a tiranizar las pasiones de los hombres, apartan de su vista al jefe que los domina. Con el mismo designio eran enteramente obscuros los templos de los Gentiles. Los Druidas celebraban sus sacrificios en el centro de los bosques más obscuros y a la sombra de las más viejas y copadas encinas.

El desorden es también compatible con la grandeza y la da con frecuencia algún realce. Pocas cosas aparecen sublimes si son exactamente regulares y metódicas. ${ }^{54} \mathrm{~A}$ su vista, nos sentimos confinados y no queda lugar al ánimo para hacer grandes esfuerzos. La proporción exacta de las partes entra a veces en la composición de lo bello; pero es muy desatendida en lo sublime. Una gran masa de rocas, esparcida por manos de la naturaleza con irregularidad y desorden, ensanchan mas el ánimo que un conjunto de ob-

51 Blair dice respecto a Burke: «...me parece sin embargo, que da demasiada extensión a su teoría, cuando hace consistir enteramente el sublime en los modos de peligro o de pena: porque la sensación propia de la sublimidad se distingue muy bien de cualquiera de estas sensaciones; y a veces está enteramente separada de ellas». (Lecciones..., I, 71.)

52 «...que todas las ideas de una clase solemne y respetuosa, y que se acercan algo a lo terrible, contribuyen en gran manera al sublime; tales como la oscuridad. la soledad y el silencio». (Lecciones..., I, 61.)

53 La descripción de estos ejemplos es copia literal del libro de Blair, (Lecciones..., I, 62.)

54 «Así como la oscuridad es muy compatible con la grandeza, así también lo es el desorden; y aun frecuentemente le da algún realce. Pocas cosas aparecen sublimes, si son exactamente regulares y metódicas». (Lecciones..., I, 65). 
jetos ajustados con las más exacta simetría. Burke da una razón filosófica de ello. No es posible, dice, que un objeto hiera fuertemente el ánimo sino se acerca algo a la infinidad, lo que no se verifica en cuantos objetos se perciben exactamente sus límites a causa del orden y de la simetría. ${ }^{55}$

No deben olvidarse por último los objetos sublimes en lo moral o sentimental. Esta sublimidad nace del corazón humano puesto en acción y lleva el nombre de magnanimidad y heroísmo. Ella causa un efecto enteramente semejante a los que produce la vista de los objetos grandes de la naturaleza, llenando el ánimo de admiración y elevándolo sobre sí mismo. ${ }^{56} \mathrm{La}$ dificultad va siempre unida de la grandeza y una acción heroica no puede dejar de ser sublime. Siempre que vemos a un hombre singularmente intrépido en medio de los peligros y que superior a la pasión y del medio cuenta solo consigo sin amedrarle la misma muerte, experimentamos en nuestro corazón este sublime de sentimiento.

Sentado ya el verdadero sublime en los objetos, queda abierto el camino para encontrar la sublimidad de los escritos. ${ }^{57} \mathrm{Su}$ fundamento es preciso que estribe siempre en la naturaleza del objeto que se describe. Si el objeto no es tal que presentado a nuestros ojos o a nuestra fantasía hiera con viveza el ánimo y lo agite con fuerza, su descripción podrá ser bella mas nunca sublime. Akenside se vale del primer género de sublime, a saber de las vastas e ilimitadas perspectivas que nos ofrece la naturaleza para formar el elogio de Bruto cuando procuró dar libertad a Roma con la muerte de César. Estas son sus palabras:

55 «La infinidad es otra fuente de lo sublime, sino pertenece más bien a la última. La infinidad tiene cierta tendencia a llenar el ánimo de aquella especie de horror deleitoso, que es el efecto más propio y la prueba más segura de lo sublime...». (Burke, Indagación..., p. 89.) Blair nunca se refiere a la infinidad.

56 "Resta aun hablar de una clase de objetos sublimes; clase que se puede llamar moral o sentimental; que nace del corazón humano puesto en acción, o de ciertas afecciones y acciones de nuestros semejantes. Se verá, que estas pertenecen única o principalmente a la clase de sentimientos conocidos con el nombre de magnanimidad o heroísmo; y que obran un efecto enteramente semejante a los que produce la vista de los objetos grandes de la naturaleza, llenando de admiración el ánimo y elevándolo sobre sí mismo». (Blair, Lecciones..., I, 66-67) Burke no se interesa por la magnanimidad.

57 «...siendo mi objeto principal el placer que recibimos del discurso y los escritos». (Blair, Lecciones..., I, 55.) «Aunque la mayor parte de los críticos hayan confundido la grandeza de los objetos, cuando se presentan a la vista, y la descripción de esta misma grandeza por medio del discurso, o por escrito; $y$ en esto hayan procedido, a mi parecer, con inexactitud». (Lecciones..., I, 58) 
Tiende, ¡o mortal!, tu vista: allá la encumbra do innumerables soles y planetas y diamantinos globos sin tropiezo girando van por el inmenso espacio. ¿Acaso, dime, tan graciosa escena de majestad, que inflama y enajena, así ensancha tus nobles pensamientos; como cuando radiante se levanta de entre la nube de patriotas Bruto de dar el golpe tan fatal a César: Y alcanzando el brazo, cual eterno Jove que airado rayos contra el crimen lanza, gritando llama a Tulio y el acero purpurado blandiendo; salve, dice: ¡Oh padre de la patria! Ya en el polvo postrado está el tirano; y Roma es libre ${ }^{58}$

Del segundo género de sublime o de los objetos de terror se valen los escritores sagrados en muchas de sus páginas. Yo oigo la voz de muchas aguas y de fuertes truenos, dice el salmista. El fuego precederá sus pasos y abrasará sus enemigos. Resplandecerán sus rayos en el orbe: los vio y se conmovió la tierra. Los montes se liquidaron como cera a la vista del Señor. La Escritura sola puede darnos ideas sublimes en esta parte; pues siempre que representa a Dios como apareciéndose a hablando con los hombres, usa de todos los objetos terribles de la naturaleza para dar realce al respeto y gravedad que infunde la presencia Divina.

El tercer género de sublime, es decir el poder puesto en ejercicio se halla en las varias poesías de Fray Luís de León, mayormente en la descripción de Behemoth y Leviathan. ${ }^{59}$ Lo usa también Job en estas palabras

58 Traducción de los versos 487-500 del poema The Pleasures of the Imagination de Mark Akenside (1721-1770). Casamada extrae el fragmento del libro de Hugo Blair, Lecciones..., I: 68-69. El original del poeta inglés se puede encontrar en The Poetical works of Mark Akenside. Ed. de Robin Dix, Fairleigh Dickinson Univ. Press, 1996, p. 106: «Look then abroad through nature, to the range / Of planets, suns, and adamantine spheres / Wheeling unshaken through the void immense; / And speak, O man! does this capacious scene / With half that kindling majesty dilate / Thy strong conception, as when Brutus rose / Refulgent from the stroke of Caesar's fate, / Amid the crowd of patriots; and his arm / Aloft extending, like eternal Jove / When guilt brings down the thunder, call'd aloud / On Tully's name, and shook his crimson steel, / And bade the father of his country, hail! / For lo! the tyrant prostrate on the dust, / And Rome again is free!... /».

59 En el Libro de Job $(40,15-24)$ se encuentra la siguiente descripción del monstruo mítico Behemot: «Fíjate en el monstruo Behemot,/criatura mía igual que tú:/come hierba, como 
«Cuando en la plaza me preparaban mi silla, veíanme los jóvenes y se ocultaban. Los príncipes cesaban de hablar y ponían el dedo en su boca: los magnates reprimían su voz y su lengua quedaba pegada al paladar». ${ }^{60}$

los bueyes;/mira qué fuertes son sus lomos/y qué poderosos sus músculos./ Su cola es dura como el cedro/y los tendones de sus patas forman nudos./Sus huesos son como tubos de bronce,/como barras de hierro./Es mi obra maestra,/y solo yo, su creador, puedo derrotarlo./De los montes, donde juegan las fieras,/le traen hierba para que coma./ Se echa debajo de los lotos,/se esconde entre las cañas del pantano./Los lotos le dan sombra,/los álamos del arroyo lo rodean./Si el río crece, no se asusta;/aunque el agua le llegue al hocico, está tranquilo./¿Quién es capaz de atraparlo y sacarle los ojos,/o de pasarle un lazo por la nariz?». (Trad. Biblia Interconfesional).

El hebreo hace el plural de la palabra b'hemahh como Behemoth. En el texto bíblico este monstruo siempre es nominado en plural, como si se le quisiera darle una magnificencia y una relevancia que el singular no posee. A fray Luis de León no le pasó inadvertido y en su comentario al libro de Job comentó: «Behemoth es palabra hebrea, que es como decir bestias; al juicio común de todos sus doctores, significa elefante, llamado ansí por su desaforada grandeza, que siendo un animal vale por muchos. Pues en decir ves, le dice dos cosas: una, que en este animal, que por su grandeza no es uno, sino muchos juntos, verá lo mucho que sabe y puede Dios, pues le hace y deshace cuando y como le place; y a este fin le pinta extensamente como es, refiriendo todas sus partes; otra, que en él conocerá cuán proprio le es a Dios amansar lo soberbio, pues hace que coma heno una bestia tan fiera. Y ansí dice yerba como buey come, porque en los animales, entre otras diferencias, hay ésta: que unos se mantienen de yerba, y éstos son más domésticos; y otros de carne, y éstos son fieros y crueles, conforme al mantenimiento que usan; y al elefante, que ansí por su grandeza de cuerpo como por su coraje de ánimo le conviene lo fiero y lo bravo, le trata Dios como si fuese buey manso, y le mantiene con heno». (Obras completas castellanas de Fray Luis de León, vol. II, Madrid, BAC, 1991, en especial el comentario 10 en el cap. 40 del libro de Job). La exposición entera de Fray Luis es interesante para contextualizar el texto Casamada.

Casamada cita también a Leviatán. En el Libro de Job (40,25-32) se presenta de esta manera: «Y a Leviatán, ¿lo pescarás con un anzuelo?/¿Podrás atarle la lengua con una cuerda?/¿Podrás pasarle un cordel por las narices/o atravesarle con un gancho la quijada?/¿Acaso va a rogarte que le tengas compasión,/a suplicarte con palabras tiernas?/¿Acaso harás que te prometa/ser tu esclavo toda la vida?/¿Jugarás con él como con un pajarito?/¿Lo atarás como un juguete de tus hijas?/¿Se pondrán a regatear por él en el mercado?/¿¿Lo cortarán en pedazos para venderlo?/¿Podrás atravesarle la piel con flechas/o la cabeza con arpones?/Si llegas a ponerle la mano encima,/te dará tal batalla que no la olvidarás,/y nunca volverás a hacerlo». (Trad. Biblia interconfesional).

Presentamos el fragmento del comentario de Fray Luis de León que Casamada tiene la mente en el momento de redactar su lección: «Pues de estos animales habla agora aquí Dios, como de obras suyas maravillosas; porque ansí la desmedida grandeza de sus cuerpos, como las figuras de sus miembros extraordinarias, son cosas de espanto y que hacen por mil razones argumento claro y certísimo, no sólo de que Dios sabe y puede mucho, sino también de lo poco que el hombre vale, pues no allega a poder mirar sin temor lo que Dios hace como por juego". (Obras completas castellanas de Fray Luis de León, vol. II, BAC, 1991, comentario 20 al cap. 40 del libro de Job). Casamada copia el ejemplo de Burke, Indagación..., II, V, p. 75.

60 Libro de Job, 29, 7-10. 
La obscuridad, la soledad y el silencio cuarto género del sublime se ve empleado por Virgilio, cuando introduce su héroe en las regiones infernales y le revela los secretos de lo porvenir en su familia y en su pueblo. La Poesía es muy feliz en este sublime. Sus apariciones, sus quimeras, sus harpías y sus figuras alegóricas son grandiosas e impresionan en corazón. Oigamos a Virgilio:

Dioses, a quién la suerte dio el gobierno de las almas; $y$ vos, oh sombras mudas, tu, Caos, tu Flegetón, vos, oh infernales playas, donde siempre hay silencio eterno, dadme licencia de decir lo visto: ${ }^{61}$ tened a bien que dé noticia al mundo de lo que el centro de la tierra encierra, y oscuridad de eterna noche esconde.

Iban los dos por la región escura, reino del gran Plutón, vacío de cuerpos, cercados de tiniebla y negra sombra. Tal era aquel camino por donde iban, Cuál es el de una espesa selva umbrosa Cuando la luna muy menguante y vieja $\mathrm{Da}$ al mundo escasa luz y amortiguada ${ }^{62}$

Es justamente celebrada la descripción que hace Milton de Satanás por el desorden que se descubre en ella y por las ideas de infinidad que encierra en sí, que es el quinto género del sublime:

\section{Como soberbia y elevada torre}

El entre los demás sobresalía por su gran talla y continente fiero; No había aún perdido enteramente su brillo primitivo, y denotaba

Ser no menos que Arcángel arruinado y una excesiva gloria escurecida; Como el sol aparece entre las nieblas, poco después que la rosada aurora, con sus brillantes rayos despuntados; O cuando encapotado en triste eclipse

61 Error: ha ser oído, tanto en el original de Virgilio como siguiendo la traducción que utiliza Casamada.

62 Eneida VI, versos 264-271. El ejemplo se encuentra en Burke, Indagación..., II, VI, p. 87. En el original, Burke sólo cita hasta el verso 269, pero Casamada la alarga un par de versos más, y lo hace utilizando la traducción que de Virgilio hizo Gregorio de Hernández de Velasco (La editio princeps es de 1555), utilizada por el mismo traductor de Burke. 
se esconde á la mitad de las naciones, y una funesta y media luz esparce por detrás de la luna y anunciando mudanzas y trastornos en la tierra, de dudas llena y miedo a los monarcas. ${ }^{63}$

La respuesta de porqué preguntado Poro por Alejandro como quería ser tratado en su cautiverio, contesto: Como Rey ${ }^{64}$ es un bello ejemplo del sublime moral o de la magnanimidad y heroísmo. Lo es igualmente la reprehensión de Cesar al Piloto que tenía naufragar con él en una tormenta. ¿Qué temes?, le dice Llevas al Cesar. ${ }^{65}$ Con este mismo sublime se expresa una joven de 16 años, a quien el coronel Bridvey, durante la revolución de Inglaterra, prometió salvar la vida de sus padres si consentía en sus torpes deseos. jInfame! Le dice ¿Quieres que un delito sea el instrumento de una acción generosa? Padres míos!... ;Qué triste es mi situación! Yo puedo salvaros... pero ¿con que medio? ;Ah! Con la infamia! No, no lo baré. Morid inocentes, que yo conservaré la virtud en medio de la desgracia. Esperadme en la mansión de los justos; pronto se reunirá con vosotros esta hija infeliz. ${ }^{66}$ Con estos ejemplos se ve claramente que para hacer una descripción sublime es menester lo sea también el objeto en sí; pero no basta ello: es preciso además que esté descrito con fuerza, concisión y sencillez. El que habla con languidez no puede inspirarnos una conmoción fuerte. ${ }^{67}$ No hay descripciones más sublimes que las de la Escritura Santa; y no por otra razón dicen todos los humanistas que por concisión y sencillez. Oigamos a Habacuc: Le presentó el Señor y midió la tierra. Miró y disolvió las Naciones: los montes eternales fueron hechos polvo. Se encorvaron los collados del mundo, dejando sus primeros caminos. Las montañas temieron y tembla-

63 Ejemplo y traducción en Burke, Indagación..., II, IV, p. 67.

64 Copiado de Blair, Lecciones..., I, p. 67

65 Idem.

66 Repetirá este mismo ejemplo en su Curso elementar de elocuencia, p. 151.

67 «Volvamos ahora a la idea, propia y natural del sublime en la composición. Su fundamento es, preciso que estribe siempre en la naturaleza del objeto descrito. Si el objeto no es tal, que, presentado a nuestros ojos, o manifestado en realidad, excite en nosotros ideas de una clase respetuosa, magnífica, y que eleva, y a las cuales damos el nombre de sublimes; su descripción, por delicadamente dibujada que esté, no es acreedora a colocarse entre ellas. [...] En segundo lugar, no solo es preciso que el objeto sea en sí sublime; sino que esté presentado en el aspecto más propio para darnos de él una impresión clara y llena: y para esto es precio que esté descrito, con fuerza, concisión y sencillez [...] Si siente con languidez, no puede inspirarnos una conmoción fuerte». (Blair, Lecciones..., I, 76-77.) 
ron: pasó por ellas un diluvio de aguas. Clamó el abismo y levantó sus manos hasta el cielo ${ }^{68}$ Dios dice el Salmista, hace cesar el bramido de los mares, la rabia de sus aguas y los tumultos del pueblo. ${ }^{69}{ }_{i}$ Cuán sublime es el unir tres objetos tan grandes, cuales son el bramido de los mares, la rabia de las aguas y los tumultos del pueblo. No hay palabra alguna superflua y excite entre ellas tanta semejanza que con la mayor naturalidad se asocian en la fantasía. Se representan por último estas cosas como sujetas al precepto de Dios, lo que produce un excelente efecto.

Vemos ya en varios de nuestros escritos repetidos ejemplos del sublime, de este don precioso, como lo llama Addison, que mueve, agita y trastorna el corazón, que trasporta al hombre fuera de sí mismo, que lo subyuga y arrastra con una fuerza irresistible. ${ }^{70}$ Por él prosperará nuestra literatura y recobrará las ventajas que perdió en los días aciagos que tiranizaron los ingenios españoles».

\section{REFERENCIAS BIBLIOGRÁFICAS}

Аввотт, Don Paul, 1989, «The influence of Blair's Lectures in Spain». Rhetorica: A Journal of the History of Rhetoric, 7/3 (Summer 1989): 275-289.

Аввотт, Don Paul, 1998, «Blair 'Abroad'; The European Reception of the Lectures on Rhetoric and Belles Lettres». En Lynée Lewis-Gaillet, Scottish Rhetoric and its Influences. New Jersey, Hermagoras Press: 67-78.

Abellán, José Luis, 1984, Historia crítica del pensamiento español. IV: Liberalismo y romanticismo (1808-1874). Madrid, Espasa-Calpe.

AdDison, Joseph, 1839, Moral and Humorous also Essays on Imagination and Taste, Edinburgh, W. \& R. Chambers.

Akenside, Mark, 1996, The Poetical works of Mark Akenside. Ed. de Robin Dix. Fairleigh Dickinson Univ. Press.

Alcalá Galiano, Antonio, 1845, Historia de la literatura española, francesa, inglesa e italiana en el siglo XVIII. Madrid, Imprenta de la sociedad literaria y tipográfica. [Lecciones pronunciadas en el Ateneo de Madrid por Antonio

68 Libro de Habacuc, 3, 6-10. El ejemplo ya se encuentra en Blair, Lecciones..., I, 79. Casamada actualiza la traducción.

69 Citado por Hugo Blair, Lecciones..., I, 79-80.

70 Casamada, Manuel, Curso elementar de elocuencia, Barcelona, Imprenta de José Torner, 1827: «Por esto se llama sublime, convenciendo que da el alma a la elocuencia, convenciendo el entendimiento y arrastrando la voluntad». (p. 143). «Los pensamientos sublimes hieren el ánimo con la mayor fuerza y lo elevan sobre sí mismo». (p. 148). 
Alcalá Galiano, redactadas taquigráficamente por Nemesio Fernández Cuesta y corregidas por el autor, 1. ${ }^{\text {e }}$ ed. 1844].

Alcalá Galiano, Antonio, 1878, Recuerdos de un anciano. Madrid, Imprenta Central.

Barraquer Roviralta, Cayetano, 1906, La casa de religiosos de Cataluña durante el primer tercio del siglo XIX. Barcelona, Altés y Alabart. Vol. 1.

BLAIR, Hugh, 1783, Lectures on Rhetoric and Belles Lettres. Dublin, Mesrr. 3 vols. [Lecciones sobre la Retórica y las bellas artes, traducidas y adicionadas a partir del original inglés de Hugo Blair. Trad. y ad. de José Luis Munárriz. Madrid, Imp. de Antonio Cruzado, 1798-1801. 4 vols.]

BurKe, Edmund, 1981- , The Writing and Speeches of Edmund Burke. Oxford, Oxford University Press. 9 vols.

Burke, Edmund, [1756], A Philosophical Enquiry into the Origin of Our Ideas of the Sublime and Beautiful. [Indagación filosófica sobre el origen de nuestras ideas acerca de lo sublime y de lo bello. Madrid, Alianza Editorial, 2014.]

Carreras i Bulbena, Josep Rafael, 1928, «Estudis biogràfics d'alguns benemèrits patricis qui ilustren aquesta Acadèmia.» Boletín de la Real Academia de Buenas Letras de Barcelona, 13/100-101 (1927-1928): 377-379.

Casamada y Comella, Manuel, 1827, Curso elementar [sic] de elocuencia. Barcelona, Imprenta de José Torner. 248 p.

Casamada y Comella, Manuel, 1828, Curso elementar [sic] de poesía. Barcelona, Imprenta de José Torner. 386 p.

Casamada y Comella, Manuel, 1829, Curso de gramática latina: según el método de las gramáticas de las lenguas vivas. Barcelona, Imprenta de Manuel Saurí. Vol. I: 323 p.; vol. II: 225 p.

Checa Beltrán, José, 1998, Razones del buen gusto (poética española del neoclasicismo). Madrid, CSIC.

Corominas, Juan, 1849, Suplemento a las Memorias para ayudar a formar un diccionario crítico de los escritores catalanes, $y$ dar alguna idea de la literatura de Cataluña, que en 1836 publicó el excmo. e ilmo. Señor Don Felix Torres Amat... Burgos, Imprenta de Araniz.

DíAZ-PlajA, Guillem, 1962, «Una càtedra de retòrica, 1822-1835». Boletín de la Real Academia de Buenas Letras de Barcelona, 29 (1961-1962): 47-79.

Elías DE Molins, Antonio, 1889, Diccionario biográfico y bibliográfico de escritores $y$ artistas catalanes del siglo XIX. Barcelona, Imprenta F. Giró e Imprenta de Calzada. 2 vols.

Feliu i MonTfort, Gaspar, 1972, La clerecia catalana durant el Trienni Liberal. Barcelona, Institut d'Estudis Catalans.

FURRIOls, Miquel, 1955, «La junta corregimental de Vich en la Guerra de la Independencia». Ausa, 2/12 (1955): 67-79. 
Garí y Siumell, José Antonio, 1875, Biblioteca mercedaria, ó sea escritores de la Celeste, Real y Militar Orden de la Merced, redención de cautivos, con indicación de sus obras, tanto impresas como manuscritas, su patria, titulos, dignidades, hechos memorables, época y provincia en que florecieron y murieron $y$ dos copiosos indices, uno de escritores y otro de las obras y escrito. Barcelona, Imprenta Herederos de la Viuda Pla.

Gazulla, Faustino D., 1930, «Los mercedarios en la Real Academia de Buenas Letras de Barcelona», Boletín de la Real Academia de Buenas Letras de Barcelona, 14/103: 122-125.

Hernández Guerrero, José Antonio y María del Carmen García Tejera, 1994, «Propuestas para una nueva lectura de las retóricas y poéticas españolas del siglo XIX.» En B. Schlieben-Lange y otros, eds., Europaïsche Sprachwissenschaft um 1800. Methodologische und Historiographische Beiträge zum umkreis der Ideologie, 2, Munich, Nodus Publikationem: 65-83.

MANDRELl, James, 1993, «Lo sublime literario en la poesía española de los siglos XVIII y XIX: Meléndez Valdéz y Espronceda». En Ermanno Caldera y Rinaldo Froldi, coords., EntreSiglos. Actas del Congreso Entre Siglos: Cultura y literatura en España desde finales del siglo XVIII a principios del XIX (Bordighera, 3-6 abril de 1990). Roma, Bulzoni: 207-216.

Menéndez y Pelayo, Marcelino, 1994, Historia de las ideas estéticas en España, CSIC, Madrid. Vol. 1.

Milà y Fontanals, Manuel, 1848, Manual de Estética. Barcelona, Imprenta Pons.

Palomeque Torres, Antonio, 1970, El Trienio Constitucional en Barcelona y la instauración de la Universidad de segunda y tercera enseñanza. Barcelona, Facultad de Filosofía, Universidad de Barcelona.

Palomeque Torres, Antonio, 1974, Los estudios universitarios en Cataluña bajo la reacción absoltista y el triunfo liberal hasta la reforma de Pidal (1824-1845). Barcelona, Facultad de Filosofía, Universidad de Barcelona.

Ramisa Verdaguer, Maties, 1984, «Aspectes de la Guerra del Francès a Vic (18081814)». Ausa, 11/110-111 (1984): 239-249.

Rico Verdú, José, 1973, La retórica española de los siglos XVI y XVII. Madrid, CSIC.

Roca i Vernet, Jordi, 2007, Política, liberalisme i revolució. Barcelona, 18201823, Barcelona, Universidad Autónoma de Barcelona (Tesis).

Rodríguez SÁnchez de LeÓn, María José, 1992, «Los 'Principios de Retórica y Poética’ de Francisco Sánchez Barbero (1764-1789) en el contexto de la preceptiva de la época». En Antonio Vilanova, coord., Actas del X Congreso de la Asociación Internacional de Hispanistas, Barcelona, PPU. Vol. 2: 1439-1450.

Rodríguez SÁNCHez de LEÓn, María José, 1993, «Batteux y Blair en la vida literaria española a comienzos del siglo XIX». En Ermanno Caldera y Rinaldo Froldi, coords., EntreSiglos. Actas del Congreso Entre Siglos: Cultura y litera- 
tura en España desde finales del siglo XVIII a principios del XIX (Bordighera, 3-6 abril de 1990). Roma, Bulzoni: 227-235.

Roviró Alemany, Ignasi, 2011 «Hug Blair a Catalunya: el discurs sobre El bell $i$ el sublim de Manuel Casamada i Comella». En Ignasi Roviró, ed., Estètica catalana, estètica europea. Estudis d'estètica: entre la tradició i l'actualitat. Barcelona, PPU: 43-80.

Rubió y Ors, Joaquín, 1887, Noticia de la vida y escritos de D. Manuel Milá y Fontanals. Barcelona, Jaime Jepús Roviralta.

SÁEZ-Rico, Alfredo, 1973, La educación general en Cataluña durante el Trienio Constitucional. Barcelona, Facultad de Filosofía y Letras, Universidad de Barcelona.

SAINT Girons, Baldine, 2005, Le sublime de l'Antiquité à nos jours. Paris, Desjonquères.

Simón DíAZ, José, 1959, Historia del Colegio Imperial de Madrid. Madrid, CSIC.

Soria Ortega, Andrés, 1979, «Notas sobre Hugo Blair y la retórica española en el siglo XIX». En Nicolás Marín, Andrés Soria y Antonio Gallego Morell, coords., Estudios sobre la literatura y arte: dedicados al profesor Emilio Orozco Diaz. Granada, Universidad de Granada. Vol. 3: 363-388.

TORRes AMAT, Félix, 1836, Memorias para ayudar a formar un diccionario crítico de los escritores catalanes, y dar alguna idea de la literatura de Cataluña. Barcelona, Imprenta de J. Verdaguer.

URZAINQUI, Inmaculada, 1989, «Batteux español». En Francisco Lafarga, ed., Imágenes de la Francia en las letras hispánicas. Barcelona, PPU: 239-260.

Wilbanks, Charles, 2005, «La retórica cristiano-humanística de Antonio de Capmany». En Helena Beristain y Gerardo Ramírez, compiladores, Los ejes de la retórica. México, Universidad Nacional Autónoma de México: 277-294. 